\title{
Anti-Fertility Effects of Nicotiana tabacum Leaf Smoke on the Spermatogenic Cells of the Adult Male Wistar Rats Testis
}

\author{
Sebastine Uche Ozioko', Onyinye Mary Ozioko², Christian Ejuiwa Mba², Ignatius Ikemefuna Ozor ${ }^{3}$, Anthony \\ Akpa $^{4}$ \\ ${ }^{1}$ Lecturer II, Department of Anatomy, College of Medicine, Enugu State University of Science and Technology, Enugu \\ State, Nigeria \\ ${ }^{2}$ Assistant Lecturer, Department of Anatomy, College of Medicine, Enugu State University of Science and Technology, \\ Enugu State, Nigeria \\ ${ }^{3}$ Senior Lecturer, Department of Anatomy, College of Medicine, Enugu State University of Science and Technology, \\ Enugu State, Nigeria \\ ${ }^{4} \mathrm{HOD}$, Department of Anatomy, College of Medicine, Enugu State University of Science and Technology, Enugu State, \\ Nigeria
}

*Address for Correspondence: Dr. Christian Ejuiwa Mba, Assistant Lecturer, Department of Anatomy, College of Medicine, Enugu State University of Science and Technology, Enugu State, Nigeria

E-mail: dogo4all@yahoo.com

Received: 19 Jan 2020/ Revised: 26 Mar 2020/ Accepted: 29 Apr 2020

\begin{abstract}
Background: Nicotiana tabacum is one of the most studied vegetables in applied and basic research. A wide range of effect of nicotine has been reported in humans and several target organs. The present study was undertaken to investigate the effect of $N$. tabacum leaf smoke on sperm parameters of adult male wistar rats.

Methods: Total 36 male wistar rats (220 to $250 \mathrm{~g}$ ) were used for the study. The experiment involved three stages: stage 1 lasted for 1 week, stage 2, a period of 2 weeks and stage 3, a period of 4 weeks. The rats were randomly divided into three groups ( 1 , 2 and 3) with 12 rats in each group, and subgroups (A, B, C and D) of 3 rats in each group. Subgroups $A$ served as a control, subgroups $B, C$, and D were the experimental groups. Rats in subgroups A were exposed to $0.5 \mathrm{~g}$ of sterile cotton wool smoke, subgroups $B, C$ and D were exposed to $0.2 \mathrm{~g} / \mathrm{kg}$ bw, $0.4 \mathrm{~g} / \mathrm{kg}$ bw and $0.8 \mathrm{~g} / \mathrm{kg}$ bw of $N$. tabacum dry leaf smoke, respectively, mixed with $0.5 \mathrm{~g}$ of sterile cotton wool.

Results- Our results showed that doses of 0.4 and $0.8 \mathrm{~g} / \mathrm{kg}$ bw of the extract increased significantly the percentage, abnormal motility $(P<0.05)$ from $30.5 \pm 1.0$ at the end of week $1\left(1^{\text {st }}\right.$ stage) to $65.6 \pm 0.8$ at the end of week 4 ( $3^{\text {rd }}$ stage), while the sperm concentration was significantly decreased $(P<0.01)$ from $347.5 \pm 43.1\left(\mathrm{ml}^{-1}\right)$ at week 1 to $107.5 \pm 2.00$ for the week 4 . There was decrease in spermatogonic cells at doses of $0.4 \mathrm{~g} / \mathrm{kg}$ bw and $0.8 \mathrm{~g} / \mathrm{kg} \mathrm{bw}$ ( $4^{\text {th }}$ week).

Conclusion- $N$. tabacum smoke extract could adversely affect the fertility of adult male wistar rats in a dose- and time-dependent manner.
\end{abstract}

Key-words: Fertility, Nicotiana tabacum, Nicotine, Spermatogenic cells, Testis, Wistar rat

\section{INTRODUCTION}

According to World Health Organization (WHO), tobacco use is described as the single most important preventable risk to human health in the developed countries and cause of premature death worldwide ${ }^{[1]}$.

\section{How to cite this article}

Ozioko SU, Ozioko OM, Mba CE, Ozor II, Akpa A. Anti-Fertility Effects of Nicotiana tabacum Leaf Smoke on the Spermatogenic Cells of the Adult Male Wistar Rats Testis. SSR Inst. Int. J. Life Sci., 2020; 6(3): 2579-2587.

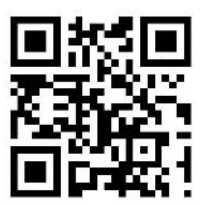

Tobacco is the name of genus Nicotiana of the Solanaceae family and the product manufactured from its leaf includes cigars, cigarettes, snuff and chewing tobacco ${ }^{[2]}$ (Johannes). Tobacco products are categorized into smoked (combustible) and smokeless tobacco. Smoking tobacco includes cigarette, roll-your own, cigars and pipes while smokeless tobacco comes in two different forms, which are tobacco snuff and chewing tobacco ${ }^{[3]}$. Smokeless tobacco has different nature forms, which are Ntsu in South Africa, Toombak in Sudan, plug chew in the United States and Nigeria Awuru in Igbo, Taba in Hausa and Yoruba languages ${ }^{[4]}$. Tobacco 
is consumed in every part of the world, most especially in the developing countries with a world population of about 2.4 billion, consuming tobacco, either in the form of snuff, chewing or smoking ${ }^{[5]}$. N. tabacum is listed in the Global Compendium of Weeds as an "agricultural weed, casual alien, cultivation escape, environmental weed, garden thug, naturalized, noxious weed, sleeper weed, and weed". For several hundred years it has been widely cultivated beyond its native range to produce the economically important crop tobacco but has escaped from cultivation and naturalized in many non-native regions ${ }^{[6]}$.

Different articles have demonstrated a negative impact of smoking on human semen parameters, correlated with cigarettes smoked/day and smoking duration. Most papers have argued that smokers demonstrate lower semen volume, sperm count, sperm motility and viability compared with non-smokers. In addition, smokers showed increased seminal leukocytes, oval sperm percentage, head-piece spermatozoa defects percentage and spermatozoa with cytoplasmic droplet ${ }^{[7]}$. Nicotine via its action on nAChR has been demonstrated to be neuro-protective against major neurodegenerative disorders including Alzheimer's disease ${ }^{[8]}$. N. tabacum is one of the most studied vegetables, not only in the applied research but also in the basic research. This plant is characterized by a rapid reproduction and fast growth and is easy to modify genetically ${ }^{[9]}$. The predominant effects of nicotine in humans include increased release of catecholamines into the blood-stream that increases pulse rate and blood pressures, the release of plasma free fatty acid and the mobilization of blood glucose. Either by direct injection or when smoking a cigarette actually causes vasoconstriction and increases blood pressure due to stimulation of the adrenal medulla and ganglion release of norepinephrine and epinephrine ${ }^{[10]}$. The mechanism, by which smoking affects male reproductive outcomes, has been linked to the relationship between seminal zinc levels than semen parameters. Studies have shown that smokers had lower seminal zinc level than non-smokers with associated decrease in sperm concentration, motility and morphology ${ }^{[11]}$. Therefore, this study was targeted at investigating the anti-fertility effects of second-degree exposure of $N$. tabacum on spermatogenic cells of the testis of adult male wistar rats.

\section{MATERIALS AND METHODS}

Animal management and grouping- Thirty-six male wistar rats weighing between $220 \mathrm{~g}$ to $250 \mathrm{~g}$ were used for the study. The animals were kept in a plastic cage with iron nettings placed in a well ventilated standard housing conditions, twelve hours light and twelve hours darkness. The animals were acclimatized for two weeks before the commencement of the experiment. During this period, the animals were observed to ensure that they were disease-free. They were fed with rat chows and given water ad libitum, and an ambient temperature range of 25-27 maintained at 50\% humidity. The animals were weighed with an electronic wt balance prior to the commencement and termination of the experiment.

Animals were divided into three groups (1, 2 and 3$)$ with 12 rats in each group, and subgroups $(A, B, C$ and $D)$. Thus, the subdivision included groups $(1 A, 1 B, 1 C$ and 1D), (2A, 2B, 2C and 2D), and (3A, 3B, 3C and 3D). Group $A$ served as the control, while groups $B, C$, and $D$ were the experimental groups (Table 1).

Animal treatment- The rats were exposed to varying doses of $N$. tabacum dry leaf smoke mixed with constant dose $(0.5 \mathrm{~g})$ of sterile cotton wool in a perforated plastic cage ( $2^{\text {nd }}$ degree exposure). The exposure was three times daily ( 9.00 hours, 11.00 hours and 13.00 hours) for four (4) weeks (Table 1). Each exposure lasted for 5 minutes. The exposure was done in three (3) stages with each stage for groups 1, 2 and 3, respectively as follows: All animals in stage $1(1 \mathrm{~A}, 1 \mathrm{~B}, 1 \mathrm{C}$ and $1 \mathrm{D})$ were sacrificed at the end of week 1 , all animals in stage $2(2 \mathrm{~A}, 2 \mathrm{~B}, 2 \mathrm{C}$ and $2 D)$ were sacrificed at the end of week 2 while all animals in stage $3(3 \mathrm{~A}, 3 \mathrm{~B}, 3 \mathrm{C}$ and $3 \mathrm{D})$ were sacrificed at the end of week 4 .

Collection of sperm and sperm count- The testicles of the rats were removed under xylazine anesthesia through lower abdominal incision. The excised testes were grossed, fixed in bouin's fluid and processed through paraffin block, microtomed to the desired thickness stained using Haemtoxylin and Eosin staining technique of Awvioro ${ }^{[12]}$. Sub-sequently the testes were separated from the epididymis. The sperm cells were sucked into a pre-warmed Pasteur pipette from the caudal epididymis. Each cauda epididymis was minced with surgical scissors in $5 \mathrm{ml}$ physiological saline, placed in a rocker for 10 minutes and allowed to incubate at room temperature for 2 minutes. 
After incubation, the supernatant fluid was diluted 1:20 with solution containing $5 \mathrm{~g}$ sodium bicarbonate and $1 \mathrm{ml}$ formalin (35\%) ${ }^{[13]}$.

Total sperm number was determined by using the improved Neubeuers counting chamber. Approximately $10 \mathrm{Ul}$ of the diluted sperm suspension was transferred to each counting chamber of the haemocytometer and was allowed to stand for 5 minutes. The chamber was placed under a binocular light microscope using an adjustable light source. The ruled part of the chamber was focused and the number of the spermatozoa counted in the five 16 celled squares using the method of Lorton ${ }^{[13]}$. The sperm concentration was calculated and expressed as $\mathrm{N} \times 10 / \mathrm{ml}$, where $\mathrm{N}$ is the number of spermatozoa in 16 celled squares.

Table 1: Distribution of animals grouping and treatment

\begin{tabular}{|c|c|c|c|c|c|c|}
\hline groups & subgroups & Body weight (g) & No of rats & N. tabacum & $\begin{array}{c}\text { Sterile cotton } \\
\text { (g) }\end{array}$ & Duration \\
\hline Stage 1 & $1 \mathrm{~A}$ & $200-250$ & 3 & $\mathrm{Nil}$ & 0.5 & 1 week \\
\hline \multirow[t]{3}{*}{ Week 1} & $1 B$ & $200-250$ & 3 & 0.2 & 0.5 & \\
\hline & $1 C$ & $200-250$ & 3 & 0.4 & 0.5 & \\
\hline & 1D & $200-250$ & 3 & 0.8 & 0.5 & \\
\hline Stage 2 & $2 A$ & $200-250$ & 3 & Nil & 0.5 & 2 weeks \\
\hline \multirow[t]{3}{*}{ Week 2} & $2 B$ & $200-250$ & 3 & 0.2 & 0.5 & \\
\hline & $2 C$ & $200-250$ & 3 & 0.4 & 0.5 & \\
\hline & $2 \mathrm{D}$ & $200-250$ & 3 & 0.8 & 0.5 & \\
\hline Stage 3 & $3 A$ & $200-250$ & 3 & Nil & 0.5 & 4 weeks \\
\hline \multirow[t]{3}{*}{ Week 4} & $3 B$ & $200-250$ & 3 & 0.2 & 0.5 & \\
\hline & $3 C$ & $200-250$ & 3 & 0.4 & 0.5 & \\
\hline & $3 D$ & $200-250$ & 3 & 0.8 & 0.5 & \\
\hline
\end{tabular}

Sperm Morphology and motility-Normal and abnormal spermatozoa morphology were evaluated with the aid of light microscope at $x 400$ magnification. Olympus $A \times 70$ Provis (Japan). For this study, morphological defects using the methods of Robert et al. ${ }^{[14]}$. Spermatozoa were considered abnormal morphology, if it had one or more of the following features; rudimentary tail, round head and detached head and this is expressed as a percentage of morphologically normal sperm. Sperm motility, the percentage of sperm cells in a unidirectional progressive movement over a field on a slide was observed using light microscope ${ }^{[15]}$. Drops of original dilution of the samples were placed in improved Neubauer counting chamber and the motile and immotile spermatozoa were counted per unit ${ }^{[16]}$. The percentage was calculated out of a total of 100 spermatozoa and noted.
Histological studies- At the end of each stage, the animals in both the control and experimental groups were sacrificed still under xylazine anesthesia. The testes were carefully excised from the animals and quickly transferred into a specimen bottle containing bouin's fluid for fixation. The tissues were processed using the routine paraffin histological method. Testes slices of 3 Um thicknesses obtained from tissue block via rotatory microtome stained using Haematoxylin and Eosin staining technique ${ }^{[13]}$. Photomicrograph analysis and interpretation was carried out using a microscope 5.0 digital camera.

Statistical Analysis- Statistical Package for Social Science (SPSS) for windows version 22 was applied for the analysis of the data. Results of sperm morphology and motility were analysed using student's t-test. 
Differences between the means were analysed statistically using one-way analysis of variance expressed as Mean \pm Standard deviation (SD) and presented in tables. $\mathrm{P}<0.05$ was considered significant. The obtained data were analysed using unpaired t-test according to

\section{RESULTS}

The result in Table 2 showed a slight decrease in average sperm count and motility as the dose increased over the
Marusteri and Bacarea ${ }^{[17]}$ differences between the means were further analysed statistically using one-way analysis of variance and presented as Mean \pm Standard Error of the Mean (SEM). $\mathrm{P}<0.05$ was considered significant.

specified period while the percentage of abnormal sperm increased slightly at varying doses over the same period.

Table 2: Effect of $N$. tabacum on the sperm parameters of adult male wistar rats in stage one (after one week)

\begin{tabular}{cccccc}
\hline Parameters & A & B & C & D & P-value \\
\hline Sperm count RT caudal epi (ML-1) & $381.5 \pm 4.9$ & $355.5 \pm 48.7$ & $351.0 \pm 12.7$ & $354.5 \pm 65.7$ & 0.87 \\
Sperm count LT caudal epi (ML-1) & $57.5 \pm 17.6$ & $357.0 \pm 52.3$ & $369.0 \pm 42.4$ & $340.0 \pm 21.2$ & 0.93 \\
Average sperm count caudal epi (ML- & $369.0 \pm 11.3$ & $356.5 \pm 50.2$ & $355.5 \pm 14.8$ & $347.5 \pm 43.1$ & 0.93 \\
1) & & & & & \\
Normal motility (\%) & $90.0 \pm 0.0$ & $80.0 \pm 7.0$ & $75 \pm 3.5$ & $70.0 \pm 0.0$ & 0.50 \\
Abnormal motility (\%) & $10.0 \pm 0.0$ & $27.0 \pm 53.7$ & $25.0 \pm 0.0$ & $30.0 \pm 0.0$ & 0.34 \\
Normal morphology (\%) & $92.5 \pm 3.5$ & $92.5 \pm 3.5$ & $95.0 \pm 0.0$ & $92.5 \pm 3.5$ & 0.80 \\
Abnormal morphology (\%) & $7.5 \pm 3.5$ & $7.5 \pm 3.5$ & $5.0 \pm 0.0$ & $7.5 \pm 3.5$ & 0.80
\end{tabular}

Values were expressed as mean $\pm S D, n=10, P$ value $\leq 0.05$

The result in Table 3 showed continual decrease though not statistically significant in average sperm count and motility at varying doses over longer period of time, while the percentage of abnormal sperm morphology remain on the increase across the subgroups.

Table 3: Effect of $N$. tabacum on the sperm parameters of adult male wistar rats in stage two (after 2 weeks)

\begin{tabular}{cccccc}
\hline Parameters & A & B & C & D & P-value \\
\hline Sperm count RT caudal epi (ML-1) & $277.5 \pm 10.6$ & $216.0 \pm 19.7$ & $210.0 \pm 0.0$ & $230.0 \pm 42.4$ & 0.14 \\
Sperm count LT caudal epi (ML-1) & $275.0 \pm 7.0$ & $214.0 \pm 19.7$ & $239.0 \pm 43.8$ & $224.0 \pm 33.9$ & 0.31 \\
Average sperm count caudal epi (ML- & $276.5 \pm 2.1$ & $215.0 \pm 19.7$ & $224.5 \pm 21.9$ & $227.0 \pm 38.1$ & 0.18 \\
1) & $92.5 \pm 3.5$ & $77.5 \pm 3.5$ & $65.0 \pm 0.0$ & $57.5 \pm 3.5$ & 0.80 \\
Normal motility (\%) & $8.5 \pm 3.5$ & $33.5 \pm 3.5$ & $35.0 \pm 0.0$ & $42.5 \pm 3.5$ & 0.80 \\
Abnormal motility (\%) & $92.5 \pm 3.5$ & $82.5 \pm 3.5$ & $85.0 \pm 7.0$ & $92.5 \pm 3.5$ & 0.20 \\
Normal morphology (\%) & $7.5 \pm 3.5$ & $17.5 \pm 3.5$ & $15.0 \pm 7.0$ & $7.5 \pm 3.5$ & 0.20 \\
Abnormamorphology (\%) & & & & & \\
\hline
\end{tabular}


The result in Table 4 showed significant decrease $(p<0.05)$ in the average sperm count at a much longer duration of the exposure to the tested animal, when compared with control.

Table 4: Effect of $N$. tabacum on the sperm parameters of adult male wistar rats in stage three (after 4 weeks)

\begin{tabular}{cccccc}
\hline Parameters & A & B & C & D & P-value \\
\hline Sperm count RT caudal epi (ML-1) & $350.0 \pm 42.4$ & $226.5 \pm 4.9$ & $247.5 \pm 3.5$ & $307.5 \pm 3.5$ & 0.01 \\
Sperm count LT caudal epi (ML-1) & $337.5 \pm 45.9$ & $230.0 \pm 14.1$ & $266.0 \pm 19.7$ & $307.5 \pm 17.6$ & 0.06 \\
Average sperm count caudal epi (ML- & & & & & 0.02 \\
1) & $344.0 \pm 43.8$ & $229.0 \pm 5.6$ & $257.0 \pm 11.3$ & $107.5 \pm 10.6$ & \\
Normal motility (\%) & $90.0 \pm 0.0$ & $77.5 \pm 3.5$ & $52.5 \pm 3.5$ & $35.0 \pm 0.0$ & 0.10 \\
Abnormal motility (\%) & $10.0 \pm 0.0$ & $72.5 \pm 3.5$ & $47.5 \pm 3.5$ & $65.0 \pm 0.0$ & 0.10 \\
Normal morpho (\%) & $95.0 \pm 0.0$ & $92.5 \pm 3.5$ & $95.0 \pm 0.0$ & $90.0 \pm 0.0$ & 0.12 \\
Abnormal morphology (\%) & $5.0 \pm 0.0$ & $7.5 \pm 3.5$ & $5.0 \pm 0.0$ & $10.0 \pm 0.0$ & 0.12 \\
\hline
\end{tabular}

Values expressed as mean \pm SD, $n=10, P$ value $\leq 0.05$

Histological studies- At the end of each stage, the animals in both the control and experimental groups were sacrificed still under xylazine anesthesia. The testes were carefully excised from the animals and quickly transferred into a specimen bottle containing bouin's

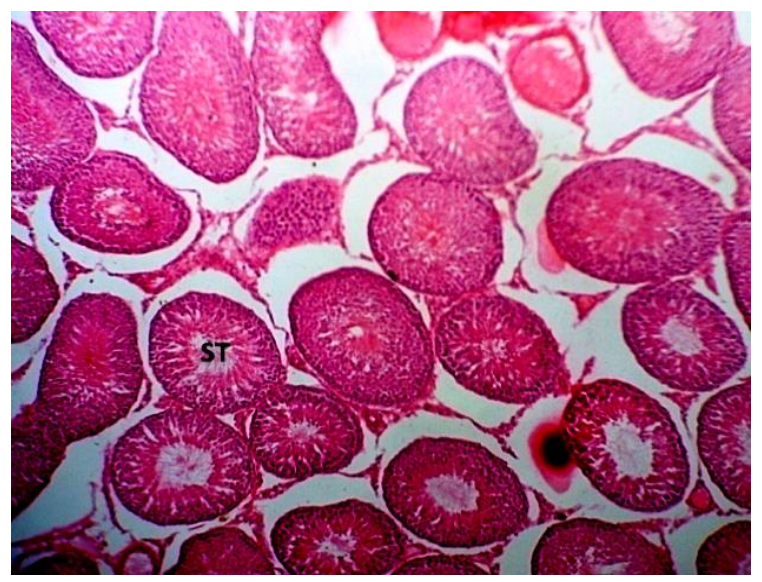

Fig. 1: Week 1 (Control); Photomicrograph of control animal testis showing normal seminiferous tubules

(ST) containing spermatozoa (H\&E stain $\times 100$ ) fluid for fixation. The tissues were processed using the routine paraffin histological method and a rotary microtome. Photomicrograph analysis and interpretation was carried out using Amscope 5.0 digital camera (Fig. 1 to Fig. 10).

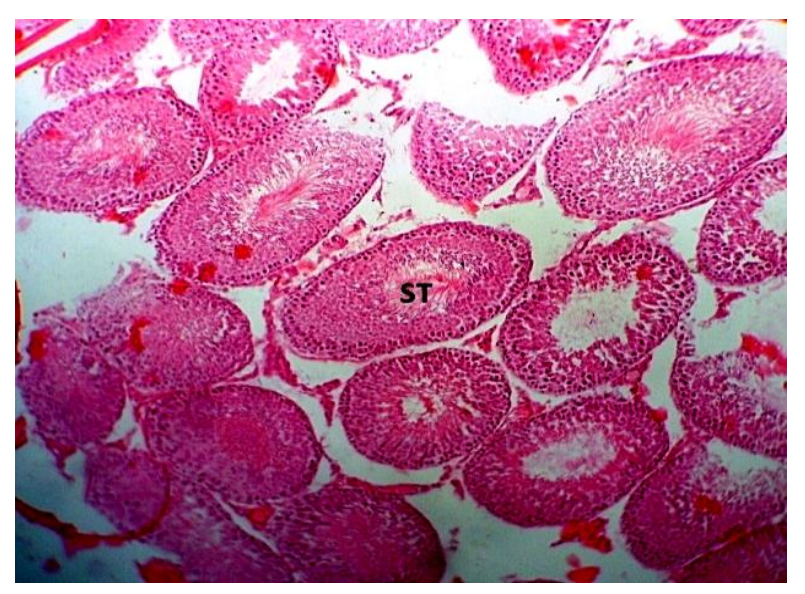

Fig. 2: Week 1 (Test); Photomicrograph of test animal testis at low dose $(0.2 \mathrm{~g} / \mathrm{kg} N$. tabacum $+0.5 \mathrm{~g}$ sterile cotton wool) showing unremarkable seminiferous tubules (ST) (H\&E stain $\times 100$ ) 


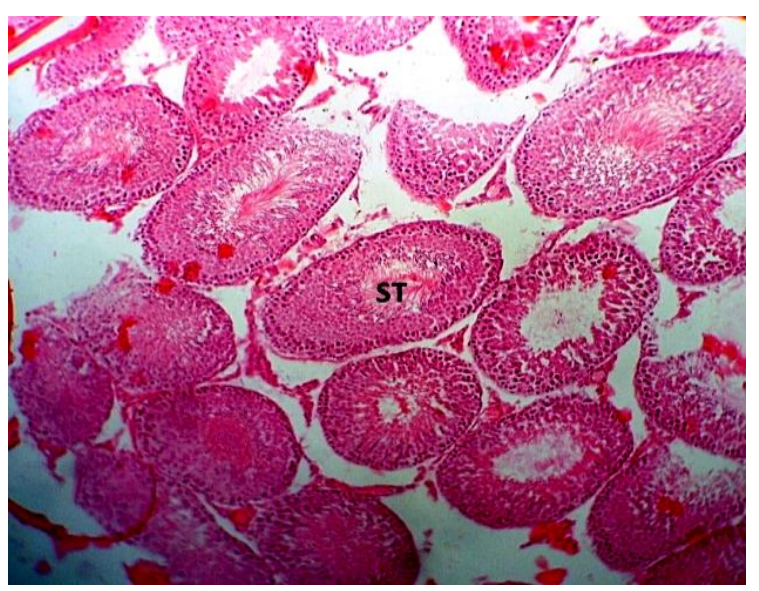

Fig. 3: Week 1(Control); Photomicrograph of test animal testis at moderate dose $(0.4 \mathrm{~g} / \mathrm{kg} \mathrm{N}$. tabacum $+0.5 \mathrm{~g}$ sterile cotton wool) showing unremarkable seminiferous tubules (ST) containing spermatozoa (H\&E stain $\times 100$ )

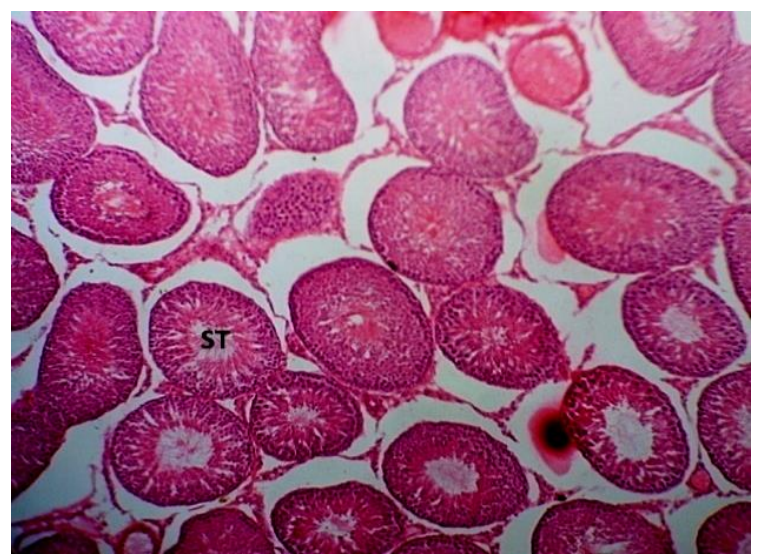

Fig. 5: Week 2 (Control); Photomicrograph of control animal testis showing normal seminiferous tubules

(ST) containing spermatozoa (H\&E stain $\times 100$ )

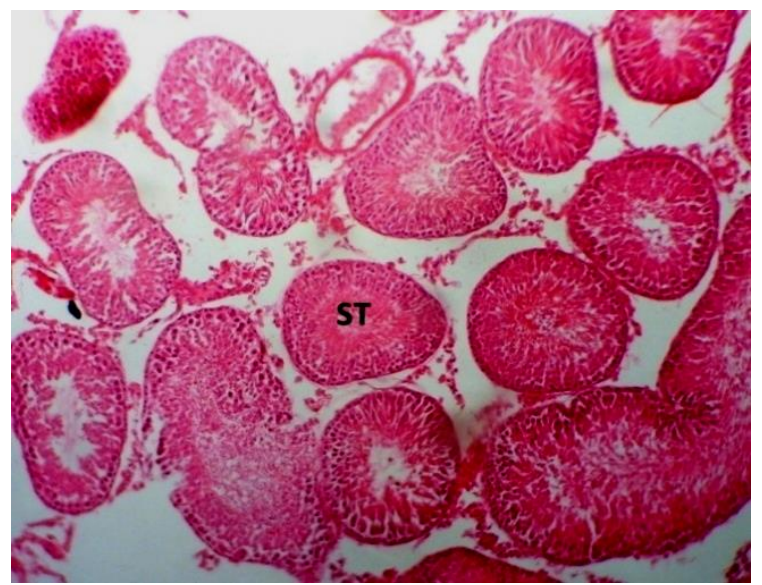

Fig. 7: Week 2 (Control); Photomicrograph of test animal testis at moderate dose $(0.4 \mathrm{~g} / \mathrm{kg} \mathrm{N}$. tabacum $+0.5 \mathrm{~g}$ sterile cotton wool) mild to moderate degeneration of seminiferous tubules (ST) (H\&E stain $\mathrm{x} 100)$

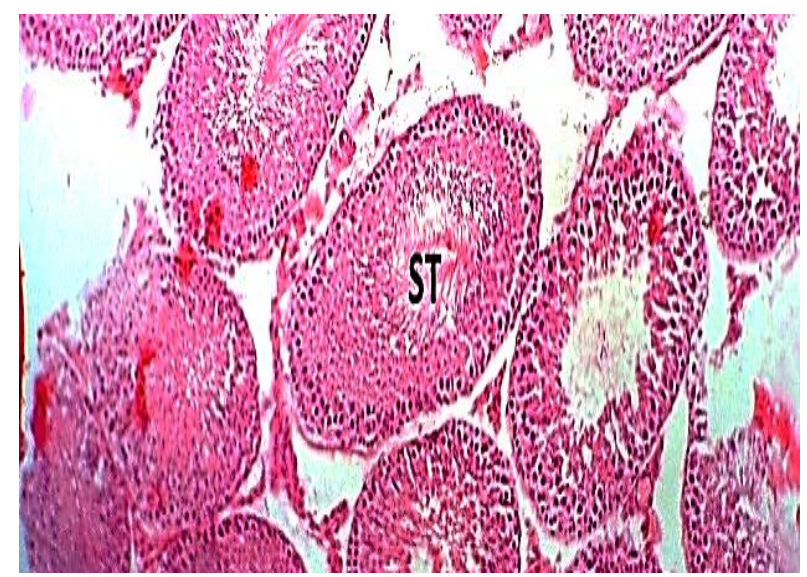

Fig. 4: Week 1( TEST): Photomicrograph of test animal testis at high dose $(0.8 \mathrm{~g} / \mathrm{kg} \mathrm{N}$. tabacum $+0.5 \mathrm{~g}$ sterile cotton wool) showing unremarkable seminiferous tubules (ST) containing spermatozoa (H\&E stain x100)

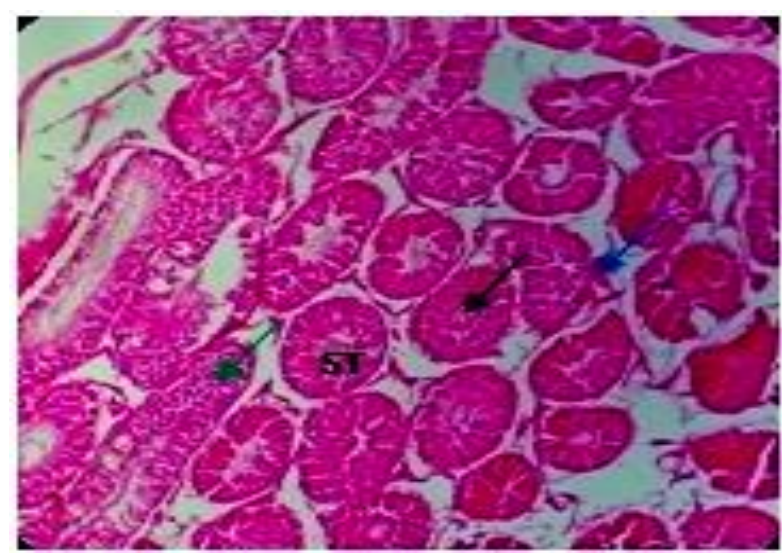

Fig. 6: Week 2 (Test); Photomicrograph of test animal testis at low dose $(0.2 \mathrm{~g} / \mathrm{kg} \mathrm{N}$. tabacum $+0.5 \mathrm{~g}$ sterile cotton wool) mild degeneration of seminiferous tubules (ST) (H\&E stain x100)

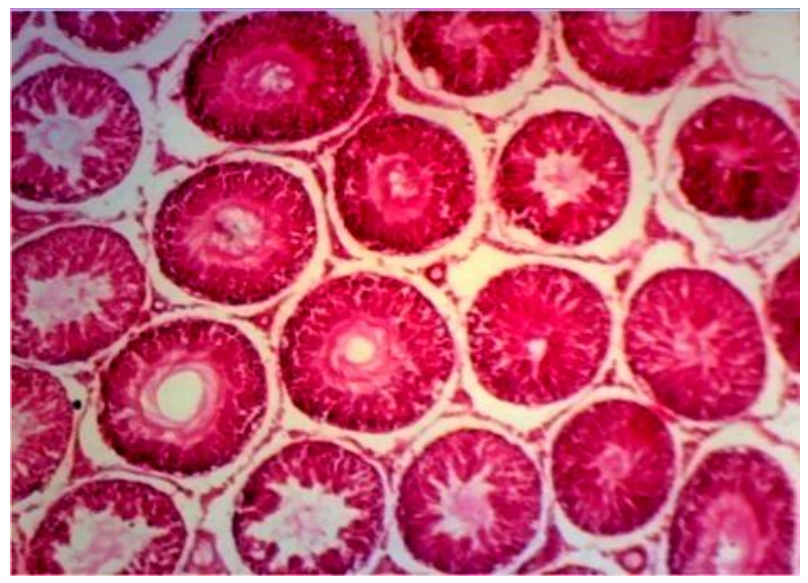

Fig. 8: Week 2 (Test); Photomicrograph of test animal testis at high dose $(0.8 \mathrm{~g} / \mathrm{kg} \mathrm{N}$. tabacum $+0.5 \mathrm{~g}$ sterile cotton wool) mild to moderate degeneration of seminiferous tubules (ST) (H\&E stain $\times 100$ ) 


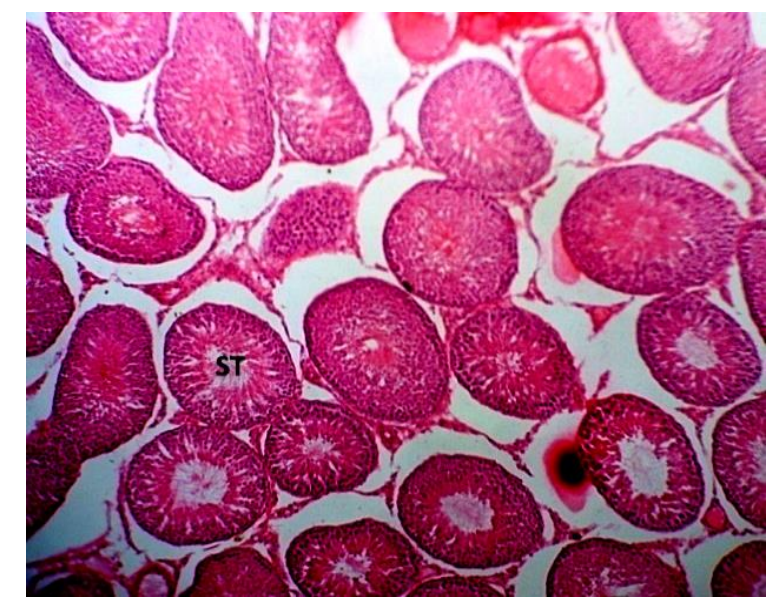

Fig. 9: Week 4 (Control); Photomicrograph of control animal testis showing normal seminiferous tubules (ST) containing spermatozoa (H\&E stain $\times 100$ )

\section{DISCUSSION}

The male reproductive system is known to be highly sensitive to many chemicals and drugs which have been found to produce an adverse effect on male reproductive capacity under certain conditions ${ }^{[18]}$ (BONDE). A consistent number of studies have claimed that cigarette smoking is correlated with alterations in sperm quality such as semen volume, sperm concentration, motility and morphology ${ }^{[11,19-23]}$. This study involved anti-fertility effects of second degree exposure of $N$. tabacum on spermatogenic cells of the testis of adult male wistar rats. Sperm motility, sperm concentration and morphology are important sperm parameter in determine male fertility. Data obtained from this study. (Table 2, 3) shows a dose and duration-dependent decrease though not statistically significant in sperm count and motility. However, Table 4 showed a significant decrease $(p<0.05)$ of sperm count and motility at week 4 of the experiment. This is in agreement with other studies that have examined the effects of cigarette smoking on male fertility, and the results have suggested a substantial negative effect on sperm production, motility, and morphology ${ }^{[24]}$. The significant decrease in motility of sperm in this study is in agreement with the work carried out by Horimoto et al. ${ }^{[25]}$ on spermatozoan abnormalities and male infertility.

The testis is the male reproductive organ and consists of seminiferous tubules, which are the sites of sperm production. The testicular histology is used to shed more light on the indices in male fertility. A cross-section of the testis shows spermatogenic cells at various stages of

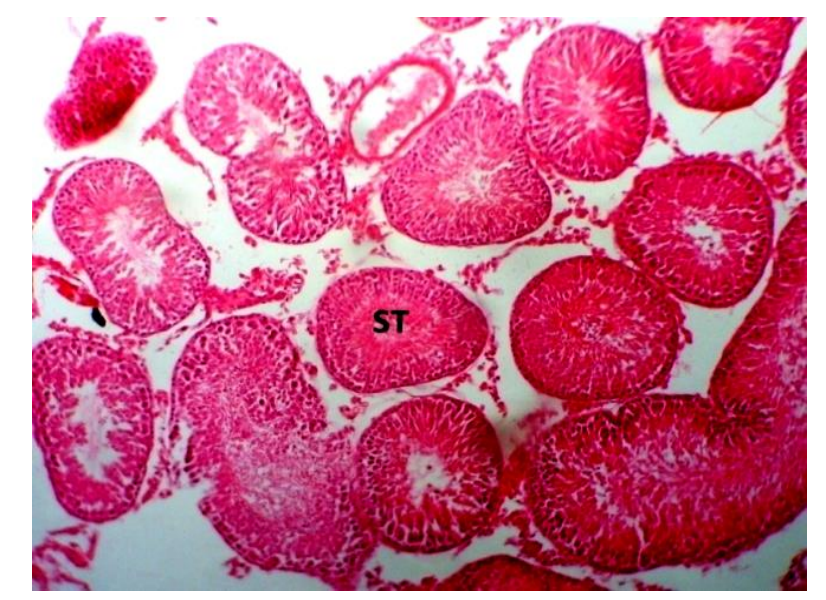

Fig. 10: Week 4 (Test); Photomicrograph of test animal testis at low dose $(0.8 \mathrm{~g} / \mathrm{kg} N$. tabacum $+0.5 \mathrm{~g}$ sterile cotton wool) showing mild to moderate degeneration of seminiferous tubules (ST) (H\&E stain $\times 100$ )

development as well as other histological components of the testis. Fig. 1 to Fig. 4 showed unremarkable histological changes, when compared with the control. However, at a longer duration of exposure and of high doses there is moderate degeneration of seminiferous tubule as depicted in Fig. 7 to Fig. 10 oral administration of nicotine has been associated with testicular degeneration and disorganization of the cytoarchitecture [16]. The rats following sulfasalazine treatment, the work revealed that on administering the drug orally, it reduced the motility of sperm and fertility of animals. It is also in agreement with the work carried out by Raji et al. ${ }^{[26]}$ on the effect of methanol extract of Ricinus communis seeds on sperm parameters.

A study examining the effect of oral nicotine on male rat found that rats exposed to oral nicotine experienced significant decrease in sperm motility and sperm count ${ }^{[26]}$. In another large cohort study, 1786 men undergoing infertility workup (655 smokers and 1131 non-smokers) [27] demonstrated that smokers was associated with decreasing sperm density (15.3\%), total sperm count $(17.5 \%)$ and total motile sperm (16.6\%) compared with non-smokers. The effect on ejaculate volume, where found in a study by Meri et al. ${ }^{[28]}$, who noted smokers had lower semen volumes per ejaculate than nonsmokers with a more specific inhibition occurring in men who smoked greater than 16 cigarettes per day. The second meta-analysis by Vine et al. [19] found that smokers had $13 \%$ to $17 \%$ lower sperm density than nonsmoker. 


\section{CONCLUSIONS}

The present study has shown that $N$. tabacum leaf smoke has adverse effects on sperm motility and spermatogenic cells of the testis. Although this $N$. tabacum is ingested via the respiratory system, its chemical contents over time diffuse into the nervous system where it can impair pituitary functions which will resultantly affect sex hormone function, thus, affecting the germinal area of the testis. This could adversely affect the fertility of individuals constantly exposed to it as carried out in this study using adult male wistar rats in a dose- and time-dependent manner. The result from this study could explain the relatively abnormal sperm parameters as seen in some chronic smokers which might lead to sub-fertility.

It is also recommended that future research on this topic or related ones that has to do with smoked leaf of $N$. tabacum should expose the animals longer than the duration animals were exposed, hormonal assay to ascertain its effect on hypothalamic-pituitary gonadal axis, and ultra structural morphological changes in spermatogenic cells using electron microscope.

\section{CONTRIBUTION OF AUTHORS}

Research concept- Sebastine Uche Ozioko, Onyinye Mary Ozioko

Research design- Sebastine Uche Ozioko, Christian Ejuiwa Mba

Supervision-Prof. Anthony Akpa, Ignatius Ikemefuna Ozor

Materials- Sebastine Uche Ozioko, Onyinye Mary Ozioko Data collection- Sebastine Uche Ozioko, Onyinye Mary Ozioko, Christian Ejuiwa Mba, Ignatius Ikemefuna Ozor

Data analysis and Interpretation- Prof. Anthony Akpa, Sebastine Uche Ozioko, Onyinye Mary Ozioko, Christian Ejuiwa Mba, Ignatius Ikemefuna Ozor

Literature search- Sebastine Uche Ozioko, Onyinye Mary Ozioko

Writing article- Prof. Anthony Akpa, Sebastine Uche Ozioko, Onyinye Mary Ozioko, Christian Ejuiwa Mba, Ignatius Ikemefuna Ozor

Critical review- Prof. Anthony Akpa, Sebastine Uche Ozioko, Onyinye Mary Ozioko, Christian Ejuiwa Mba, Ignatius Ikemefuna Ozor

Final approval- Prof. Anthony Akpa

\section{REFERENCES}

[1] Ukoha U, Uchechukwu D, Stephen M. The effect of sub-lethal doses of smokeless tobacco (snuff) on certain haematological and haemostatic parameters in wistar rats. J Exp Integr Med., 2012; 2(3): 225-30.

[2] Johannes J, Jawes JJ, Uma S, Heyan D, F-Farjado L, et al. Nicotine accelerates angiogenesis and wound healing in genetically diabetic mice. Am J. Pathol., 2002; 161: 97-104.

[3] Thomson M, Ahlbom A, Bridges J, Rydzynski K. Health effect of smokeless tobacco products. Scientific Committee on Emergency and Newly Identified Health Risk paper Brusell, 2008; pp. 1-157.

[4] Aduema W, Lelei SA, Osim EE, Koikoibo W, Nneli RO. Effect of chronic consumption of powdered tobacco (snuff) on anxiety, fear and social behaviours. Int J Basic Appl Innovat Res., 2012; 1(4): 161-69.

[5] Aghaji M. Cigarette smoking and quitting among young adults in Enugu, Nigeria. Niger Med J., 2008; 49(5): 155-56.

[6] Randall RP. A Global Compendium of Weeds. Perth, Australia: Department of Agriculture and Food Western Australia, 2nd ed., 2012; pp. 1124. http://www.cabi.org/isc/FullTextPDF/2013/2013310 9119.pdf.

[7] Mostafa T. Cigarette smoking and male infertility. J Adv Res., 2010; 1: 179-86.

[8] Hassan A, Abo SM, Azma SM, Fayed T. Seminal plasma cotinine and insulin-like growth factor-I in idiopathic oligoasthenoteratozoospermic smokers. BJU Int, 2009; 103(1): 108-11.

[9] Oberg M, Woodward A, Jaakkola M, Pruss-Ustiin A. Global estimate of the burden of the disease from second hand smoke. Geneva, World Health Organization, 2010.

[10]Tuesta LM. Recent advances in understanding nicotinic receptor signalling mechanism that regulates drug self-administration behaviour. Pharmacol. Biochem. Behav., 2011; 82(16): 984-95.

[11]Ramlau-Hansen $\mathrm{CH}$, Thulstrup AM, Aggerholm AS, Jensen MS, Toft $G$, et al. Is smoking a risk factor for decreased semen quality? A cross-sectional analysis. Hum Reprod J. 2007; 22(6):188-196.

[12]Awvioro OG. Histochemistry and tissue pathology principles and technique $1^{\text {st }}$ ed. Ibadan Nigeria, 2002; 154-162. 
[13]Lorton SP. Evaluation of Semen in the Andrology Laboratory Reproduction Resources, Walworth, Wisconsin, USA; 2017; 1: 1-8.

[14]Seed J, Chapin RE, Clegg ED, Dostal LA, Foote RH, et al. Methods For Assessing Sperm Motility, Morphology, And Counts In The Rat, Rabbit, And Dog: A Consensus Report. Reprod Toxicol., 1996; 10(3): 237-44.

[15]Omirinde JO, Olukole SG, Oke BO, et al. Age-related changes in the testicular and epididymal sperm parameters in the African greater cane rat (Thryonomys swinderianus, temminck, 1827). Animal Res Inter., 2019; 16(1): 3255-64.

[16]Oyeyipo IP, Raji Y, Emikpe BO, bolarinwa AF. Effect of oral administration of nicotine on organ weight, serum testosterone level and testicular pathology in adult male rat Niger J Psychol Sci., 2010; 25: 81-86.

[17]Marusteri M, Bacarea V. Comparing groups for statistical differences: how to choose the right statistical test?. Biochem Med (Zagreb), 2010; 20: 1532.

[18]Bonde JP. Male fertility. In. Comhaire FM, editor. Chapman and Hall Medicals. New York. Chapman and Hall, 1996; 266-84.

[19]Vine MF, Margolin BH, Morrison HI, Hulka BS. Cigarrette smoking and sperm density: A metaanalysis. Fertil Steril., 1994; 61: 35-43.

[20]Zavos P, Correa J, Antypas S, Zarmakoupis-Zavos P, Constantinos N. Effect of seminal plasma from cigarette smokers on sperm viability and longevity. Fertlil Steril., 1998; 69: 425-29.
[21]Ozgur K, Isikoglu M, Seleker M, Donmez L. Semen quality of smoking and non-smoking men in infertile couples in a Turkish population. Arch Gynecol Obstet., 2005; 271: 109-12.

[22] Guo H, Zhang HG, Xue BG, Sha YW, Liu Y, et al. Effect of cigarette, alcohol consumption and sauna on sperm morphology. Zhonghua Nan Ke Xue, 2006; 12: 215-17.

[23] Pasqualotto F, Sobreiro B, Hallak J, Pasqualotto E, Lucon A. Cigarette smoking is related to a decrease in semen volume in a population of fertile men. BJU Int., 2006; 97: 324-26.

[24]Yokoi K, Mayi ZK. Organ Apoptosis with cytotoxic drugs. Toxicol., 2004; 290: 78-85.

[25] Horimoto $M$, Isobe $Y$, Isogai $Y$, Tachibana $M$. Rat epididymal sperm motion changes induced by ethylene glycol monoethyl ether sulfasalazine and 2,5- Hexanodione. Reprod. Toxicol., 2000; 14(1) 5563.

[26]Raji Y, Oloyo AK, Morakinyo AO. Effect of methanol extract of Ricinus communis seed on reproduction of Male rats. Asian J Androl., 2006; 8(1): 115-21.

[27]Kunzle $R$, Mueller $M$, Hanggi W, Birkha"user $M$, Drescher $\mathrm{H}$, et al. Semen quality of male smokers and nonsmokers in infertile couples. Fertility Sterility J., 2003; 79(5): 287-91.

[28] Meri ZB, Irshid IB, Migdadi M, Irshid AB, Mhanna SA. Does cigarette smoking affect seminal fluid parameters? A comparative study. Oman Med J., 2012; 28(1): 12-15. 